\title{
COMBINED SLEEVE LOBECTOMY AND IVOR LEWIS ESOPHAGECTOMY FOR SYNCHRONOUS PRIMARY CARCINOMA OF THE LUNG AND BARRETT ESOPHAGUS
}

Karsten Kuhn, MD, Stefan Pasch, MD, Wlodzimierz Wojciechowski, MD, and Paolo Macchiarini, MD, PhD,

Hannover, Germany

Patients with synchronous primary lung and esophageal carcinoma usually have a history of significant tobacco and alcohol exposure, low performance status, impaired pulmonary function, and a tumor burden that does not permit potentially curative resections. ${ }^{1-3}$ Operations are seldom indicated because of the poor prognosis and

From the Department of Thoracic and Vascular Surgery, Heidehaus Hospital (Hannover Medical School), Hannover, Germany.

Received for publication Jan 18, 2000; accepted for publication Jan 25, 2000 .

Address for reprints: Paolo Macchiarini, MD, PhD, Department of Thoracic and Vascular Surgery, Heidehaus Hospital (Hannover Medical School), Am Leineufer, 70, 30419 Hannover, Germany (E-mail: pmacchiarini@compuserve.com). expected high surgical morbidity and mortality. Pneumonectomies are especially to be avoided. ${ }^{1}$ In this report, we present the surgical management of a patient with synchronous, primary, centrally located squamous cell carcinoma of the lung and esophageal adenocarcinoma with Barrett epithelium.

J Thorac Cardiovasc Surg 2000;119:1289-90

Copyright $\odot 2000$ by The American Association for Thoracic Surgery

$0022-5223 / 2000 \$ 12.00+0 \quad \mathbf{1 2 / 5 4 / 1 0 6 0 3 4}$

doi:10.1067/mtc.2000.106034 
Clinical summary. A 51-year-old man was referred to us with a history of significant cigarette smoking (30 packyears), heavy alcohol consumption, diabetes mellitus (type IIb), chronic obstructive pulmonary disease, and dilative cardiomyopathy. He had had gastroesophageal reflux for 2 years and dysphagia and substernal pain for 1 month. Chest radiography and thoracoabdominal computed tomography showed a centrally located tumor of the right lung without mediastinal involvement or enlarged lymph nodes in the upper and lower mediastinum. A sonogram of the celiac region showed no abdominal adenopathy. Examination with a rigid bronchoscope identified a squamous cell lung tumor arising from the right upper lobe and extending beyond the lobar takeoff into the distal main bronchus. Biopsy specimens of the proximal right main bronchus and origin of the intermediate bronchus revealed no cancer at those sites. Esophagogastroscopy and endoscopic ultrasonography identified a $1 \times 1-\mathrm{cm}$ polypoid intraluminal adenocarcinoma localized in the distal esophagus $30 \mathrm{~cm}$ from the incisors, without gastric involvement or extramural infiltration. Investigations in search of possible extrathoracic metastasis, including brain computed tomographic scan, bone marrow scan, and colonoscopy, showed no cancer. Assessment of the patient's overall condition revealed a stable dilative cardiomyopathy with a left ventricular ejection fraction of $32 \%$, without coronary artery disease, and liver and kidney function within normal limits. The predicted forced expiratory volume in 1 second was $66 \%$, predicted forced vital capacity was $81 \%$, and the ratio of forced expiratory volume in 1 second to vital capacity was $89 \%$. The right lung contributed $51 \%$ and $43 \%$ of the total ventilation and perfusion, respectively.

We undertook 1-stage removal of the pulmonary and esophageal neoplasms in the following sequence. We began with a laparotomy to accomplish the standard abdominal preparation of the stomach and lymph node dissection, including preservation of the omentum. An intramucosal pylorotomy was also done. Next, a right upper sleeve lobectomy and radical mediastinal lymph node resection were done via a posterolateral thoracotomy. Third, the azygos vein and thoracic ductus were doubly ligated, the esophagectomy was done, and digestive contiguity was re-established with an esophagogastric Sweet anastomosis ${ }^{4}$ above the azygos vein. All bronchial, digestive, and lymph node samples were tumor-free according to intraoperative frozen sections. The omentum was transposed between the bronchial and esophagogastric anastomotic regions. The final pathology report showed a well-differentiated squamous cell lung carcinoma with one peribronchial metastatic lymph node (pT2 N1, stage IIB) and an esophageal adenocarcinoma (pT1 N0) associated with Barrett columnarlined epithelium. The postoperative course was uneventful. The patient resumed eating 7 days after the operation and was discharged from the hospital 14 days after the operation. No postoperative chemotherapy or radiation therapy was given. $\mathrm{He}$ is alive and without evidence of disease or postoperative symptoms 10 months after the operation.
Fewer than $2 \%$ of patients with primary esophageal tumors have synchronous primary lung cancers, and most of these tumors have been of squamous cell type. ${ }^{1}$ Fewer than $60 \%$ of such patients have been treated surgically because of perceived excessive risks. This hesitancy to recommend combined lung and esophageal operations was based on previously published reports of poor long-term outcomes. ${ }^{1-3}$ Our case suggests that surgery should not be categorically denied and that carefully selected patients with synchronous primary lung and esophageal cancers should be offered potentially curative resections. The preoperative work-up should be directed at determining, insofar as possible, that neither of the two lesions is a metastasis from the other and that no occult head and neck cancer exists.

Our patient had severe respiratory dysfunction in addition to the rare association of a primary squamous cell tumor of the lung and esophageal adenocarcinoma with Barrett epithelium. Two-stage procedures for similar circumstances have been described, ${ }^{2,3}$ starting either with the lung resection or the esophagectomy. We selected a simultaneous 1-stage approach, in part to avoid a temporary esophagostomy and in part to minimize the risk of metastasis from the esophageal cancer during the interim between operations. Preoperatively, we were not sure that sleeve lobectomy would be appropriate, but in preparation for this possibility we harvested the omentum during laparotomy for the purpose of protecting the anastomoses. The lymphatic duct was doubly ligated to avoid the risk of chylothorax associated with sleeve lobectomy and radical lymph node dissection. ${ }^{1}$ The sleeve lobectomy was done first to avoid contamination of the endobronchial system when the digestive tract was opened, and the omentum was used to protect the two anastomoses. Although one may argue about the oncologic value of sleeve lobectomy, we preferred it because of the patient's poor lung function and the risks of pneumonectomy. ${ }^{1}$

In summary, a potentially curative operation was successfully done to treat synchronous primary squamous cell lung cancer and esophageal adenocarcinoma. We suggest that this approach be used for carefully selected patients who have such cancers.

\section{REFERENCES}

1. Fekete F, Sauvanet A, Kaisserain G, et al. Associated primary esophageal and lung carcinoma: a study of 39 patients. Ann Thorac Surg 1994;58:837-42.

2. Fukuda H, Ogino N, Takao T, Kobayashi S, Kido T. A case report of synchronous double cancer of the lung and esophagus. Nippon Kyobu Geka Gakkai Zasshi 1990;38:1053-8.

3. Morimoto M, Ohno T, Yamashita Y, Honda M, Asada S. Two surgical synchronous double carcinoma of the lung and the esophagus and review of 10 documented cases. Nippon Kyobu Geka Gakkai Zasshi 1991;39:245-50.

4. Mathisen D. Ivor Lewis procedure. In: Pearson FG, Deslauriers J, Ginsberg RJ, Hiebert CA, McKneally MF, Urschel HC, editors. Esophageal surgery. New York: Churchill Livingstone; 1995. p. 669-76. 